\title{
Color changes of ceramic veneers following glazing with respect to their composition
}

\author{
Sung-Joon Kim,2, Jae-Man Woo², Chan Woo Jo², Ju-Hee Park², Soo Kyung Kim³, Se Hoon Kahm, ${ }^{1,2,4}$ \\ ${ }^{1}$ Department of Dentistry, School of Medicine, Jeju National University, Jeju, Republic of Korea \\ ${ }^{2}$ Department of Dentistry, Jeju National University Hospital, Jeju, Republic of Korea \\ ${ }^{3}$ School of Medicine, Jeju National University, Jeju, Republic of Korea \\ ${ }^{4}$ Graduate School of Medicine, the Catholic University of Korea, Seoul, Republic of Korea
}

\begin{abstract}
PURPOSE. The purpose of this study was to compare the translucency and color changes of ceramic laminate veneers of different composition following glazing process. MATERIALS AND METHODS. $10 \mathrm{~mm} \times 10 \mathrm{~mm}$ square specimens of $0.6 \mathrm{~mm}$ and $1.0 \mathrm{~mm}$ thicknesses were fabricated with IPS e.max Press (EM) and IPS e.max ZirPress (ZP) ( $n=10$ per group). The color coordinates (CIE L* $a^{*} b^{*}$ ) of the specimens were recorded with a colorimeter before and after glazing. The color changes and translucency parameter (TP) were calculated. For the comparisons with the composition and thicknesses between the 'not glazed' and 'glazed' groups, statistical analyses were done through paired T-test, independent two-sample T-test, and multiple regression analysis using SPSS $18.0(P<.05)$. RESULTS. The TP of $0.6 \mathrm{~mm}$ EM was higher than that of $0.6 \mathrm{~mm}$ ZP. Total color difference $\left(\Delta \mathrm{E}^{*}\right)$ between bare and glazed specimens of $1.0 \mathrm{~mm} \mathrm{EM}$ was greater than that of $1.0 \mathrm{~mm} \mathrm{ZP}$ with statistical significance. Following glazing, specimens from all groups showed statistically significant amount of decrease in $\mathrm{L}^{*}$ and $\mathrm{a}^{*}$, and statistically significant increase in $\mathrm{b}^{*}$. The result of multiple regression analysis of EM and ZP showed that $\Delta \mathrm{L}^{*}$ improved $\Delta \mathrm{E}^{*}$. CONCLUSION. Within the limitations of present study, we conclude that translucency and color of ceramic laminate veneers change significantly after glazing process, and the nature and amount of changes vary with different compositions. [J Adv Prosthodont 2019;11:16-22]
\end{abstract}

KEYWORDS: Color; Dental veneer; Ceramic; Lithium disilicate; Fluorapatite

\section{INTRODUCTION}

In light of the recent surge of interest in and patient demand for facial and dental esthetics, it is important to give careful consideration to the color and contour of dental restorations during treatment planning in order to match the remaining tooth structure and blend well with adjacent gingival tissue. This trend has created a demand for the production of ceram-

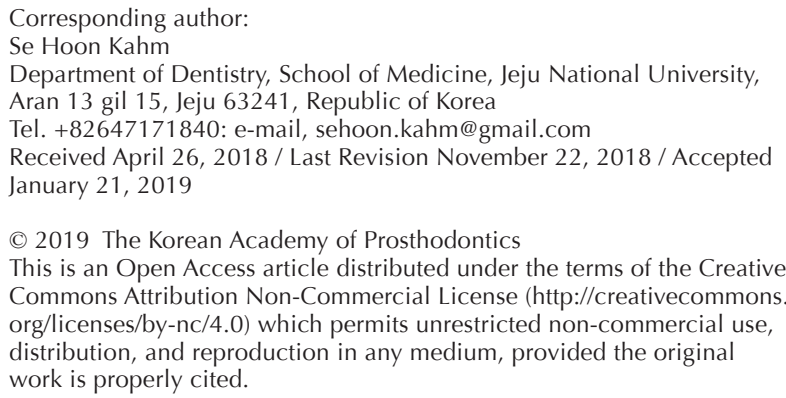

This work was supported by a research grant from Jeju National University Hospital in 2015. ic prostheses with color and translucency equivalent to natural dentition. Tooth color varies among individuals as the color of dentin showing through enamel takes on different shades depending on thickness, curvature, and surface structure. Natural dentition has unique translucency and it is essential for ceramic restorations to restore this natural color and translucency. However, the esthetic properties of natural dentition, which consist of both minimally translucent dentin and highly translucent enamel, are difficult to reproduce using single-component ceramic restorations. The production of esthetic restorations that resembles natural dentition requires not only knowledge of color science but also understanding of function and biology of teeth and periodontal tissue, ${ }^{1}$ and fabrication of such restoration involves lamination of carefully and purposefully selected materials. $^{2}$

Direct resin restorations and ceramic laminate veneers may both improve shape and color and preserve tooth structure in the anterior region. Of the two, ceramic laminate veneers are often preferred for their color stability and esthetics. The color of ceramic veneers is influenced by fir- 
ing temperature, number of firings, surface smoothness, ceramic thickness, manufacturer, and type of supporting structure. ${ }^{3}$ The color of final restoration is also affected by the type of cementation used, background color, measurement lighting, and material texture. ${ }^{4}$ The color stability of ceramic prostheses is achieved through glazing, which is the final step of ceramic production that results in lasting surface smoothness. ${ }^{5}$ Glazing process involves heating of prosthesis in a glazing oven or applying glass agent to the surface and firing it. ${ }^{6}$ Glazing takes on its effect through formation of a low-expansion surface layer at high temperatures, and it increases the surface hardness of ceramics. The more commonly utilized method is self-glazing, which involves ordinary firing without the use of glazing agent, followed by additional firing in air. $^{7}$ Laminate veneers, however, are produced without a core component, thus glazing is done by applying a separate glazing agent to the external surface only because glazing of the adhesive side is not desired. Both glazing methods exhibit certain amount of change in color. This may be due to unintended changes in ceramics containing leucite or lithium disilicate at high temperatures or may be explained by infiltration of the ceramic surface by pyroclastic streams during high-temperature firing. ${ }^{8}$

Compared to other types of prostheses, laminates are thinner and are less likely to require occlusal adjustments or other modifications after fabrication. This means that the color after glazing is the color of the final restoration in most cases. Various studies have been conducted for dental restorations with a natural color appearance. Researchers have examined optical properties to block out the background color of restored teeth, ${ }^{9-14}$ and it has been reported that a perceptible color change was observed in fully sintered zirconia ceramics after glazing. ${ }^{14}$ However, there is not enough research on the optical properties of laminates to produce color and contour of natural dentition. Research has demonstrated that glazing changes the translucency of lithium disilicate ceramic veneers with consistency among manufacturers. ${ }^{15}$ A single-thickness specimen test showed color difference before and after glazing and reported that the phenomenon is influenced by $\Delta \mathrm{b}^{*}$ and $\Delta \mathrm{L}^{*} .{ }^{16} \mathrm{~A}$ lithium disilicate study using thicknesses of $0.3 \mathrm{~mm}, 0.6 \mathrm{~mm}$, and $0.9 \mathrm{~mm}$ reported a statistically significant increase in translucency in the thinner groups $(0.3 \mathrm{~mm}$ and $0.6 \mathrm{~mm})$, with color differences and changes in color coordinates being statistically significant in all thickness groups. ${ }^{17}$ However, there are few reports concerning varying amounts of color changes depending on composition of the materials tested.

This study aims to investigate the effect of glazing on translucency and color of two different ceramic laminate veneers. The null hypotheses were: 1) compositions of ceramic laminate veneers do not affect their translucency and color change after glazing; 2) thickness of ceramic laminate veneers does not affect its translucency and color change after glazing.

\section{MATERIALS AND METHODS}

Specimens were prepared using laminate veneer restoration materials IPS e.max Press (EM, Ivoclar Vivadent, Schaan, Liechtenstein), which is made of lithium disilicate, and IPS e.max ZirPress (ZP, Ivoclar Vivadent, Schaan, Liechtenstein), which is made of fluorapatite. Glazing was performed by applying IPS e.max Ceram Glaze (Table 1). The specimens were prepared using the lost wax and heat pressing techniques according to the manufacturer's instructions. Ten square A1-shade specimens measuring $10 \mathrm{~mm} \times 10 \mathrm{~mm}$ were prepared in two different thicknesses $(0.6 \mathrm{~mm}$ and 1.0 $\mathrm{mm}$ ) using a sheet wax mold for each group (40 specimens total). Color measurements were done on unglazed specimens first. Second color measurements were performed after applying the glazing paste to only one side of the specimens and firing at $800^{\circ} \mathrm{C}$ for 1 minute in a furnace (Vita Vacumat 40, Vita Zahnfabrik, Bad Säckingen, Germany).

The ShadeEye NCC Dental Chroma Meter (Shofu inc., Kyoto, Japan), a colorimeter, was used to measure the color of the specimens. Average CIE L*a*b* values were obtained by taking three measurements of each specimen using the Analyze Mode of ShadeEye-NCC against a background panel. The color measurements were done by a single experienced analyst by zeroing the calibrating tip and uniformly contacting the middle part of each specimen. Distilled water (refractive index of 1.33) was used in compliance with the British Standard Institution as a contact medium to increase optical contact between the specimens and the background panel. ${ }^{18}$ Each specimen was measured on a white tile background panel $\left(\mathrm{L}^{*}=94.78, \mathrm{a}^{*}=-0.78, \mathrm{~b}^{*}=\right.$ -2.40). The same white tile background panel $\left(\mathrm{L}^{*}=94.78\right.$, $\left.\mathrm{a}^{*}=-0.78, \mathrm{~b}^{*}=-2.40\right)$ was used with a black tile background panel $\left(\mathrm{L}^{*}=7.58, \mathrm{a}^{*}=0.15, \mathrm{~b}^{*}=-3.15\right)$ as is necessary for translucency parameter (TP) measurement. CIE $\mathrm{L}^{*} \mathrm{a} * \mathrm{~b} *$ is a widely used color system established by the International Commission on Illumination in 1976. It gives

Table 1. Experimental materials and glazing agent information

\begin{tabular}{|c|c|c|c|c|}
\hline Material (code) & Classification & Manufacturer & Shade & Lot No. \\
\hline IPS e.max Press (EM) & Pressable lithium disilicate & Ivoclar Vivadent AG (Schaan, Liechtenstein) & A1 & L42237 \\
\hline IPS e.max ZirPress (ZP) & Pressable fluorapatite & Ivoclar Vivadent AG (Schaan, Liechtenstein) & A1 & T34720 \\
\hline IPS e.max Ceram Glaze & Glazing paste & Ivoclar Vivadent AG (Schaan, Liechtenstein) & - & K38334 \\
\hline
\end{tabular}


three-dimensional coordinates for a specific color space where the $\mathrm{L}^{*}$ value for lightness ranges from 0 for pure black to 100 for pure white, the $a^{*}$ value ranges from red (positive) to green (negative), and the $b^{*}$ value ranges from yellow (positive) to blue (negative). The color difference before and after glazing, $\Delta \mathrm{E}^{*}$, was calculated as follows:

$$
\Delta \mathrm{E}^{*}=\left[\left(\Delta \mathrm{L}^{*}\right)^{2}+\left(\Delta \mathrm{a}^{*}\right)^{2}+\left(\Delta \mathrm{b}^{*}\right)^{2}\right]^{1 / 2}
$$

The TP of each thickness was calculated as follows:

$$
\mathrm{TP}=\left[\left(\mathrm{L}_{\mathrm{W}}{ }^{*}-\mathrm{L}_{\mathrm{B}}{ }^{*}\right)^{2}+\left(\mathrm{a}_{\mathrm{W}}{ }^{*}-\mathrm{a}_{\mathrm{B}}{ }^{*}\right)^{2}+\left(\mathrm{b}_{\mathrm{W}}{ }^{*}-\mathrm{b}_{\mathrm{B}}{ }^{*}\right)^{2}\right]^{1 / 2}
$$

The subscripts $\mathrm{W}$ and $\mathrm{B}$ indicate whether the measurements were taken on a white tile background panel (W) or a black tile background panel (B). The measurement represents the color difference of the same specimen between the black and white backgrounds, where larger values indicate higher translucency and a TP of 0 indicates an opaque material. ${ }^{19}$

Statistical analyses were conducted at a significance level of 0.05 using the SPSS Win 18.0 program (SPSS Inc., Chicago, IL, USA). The difference before and after glazing for each thickness was analyzed using paired t-test, and the difference in color change before and after glazing between the materials was analyzed using independent t-test. The color coordinates were analyzed for correlation by performing a multiple regression analysis with $\Delta \mathrm{E}^{*}$ as the dependent variable.

\section{RESULTS}

Comparison of TP between the two materials of the same thickness showed that ZP was significantly higher than EM in the unglazed $0.6 \mathrm{~mm}$ and $1.0 \mathrm{~mm}$ groups and in the glazed $1.0 \mathrm{~mm}$ group, indicating a higher degree of translucency (Table 2).

TP measurements of single specimens before and after glazing showed a statistically significant increase in average TP for the $0.6 \mathrm{~mm}$ EM specimens $(P<.05)$, while the difference was borderline significant for the $1.0 \mathrm{~mm}$ EM specimens $(P=.084)$. There was an increase in the average TP in the ZP group but the difference was not statistically significant. Average TP increased after glazing by $5.48 \%$ in the 0.6 $\mathrm{mm}$ EM group, $3.24 \%$ in the $0.6 \mathrm{~mm}$ ZP group, $10.07 \%$ in the $1.0 \mathrm{~mm}$ EM group, and $0.82 \%$ in the $1.0 \mathrm{~mm}$ ZP group (Table 3, Fig. 1).

A comparison of the color space before and after glazing suggested that the $0.6 \mathrm{~mm}$ EM group became darker as indicated by the large and statistically significant decrease in the $\Delta \mathrm{L}^{*}$ value. In the $1.0 \mathrm{~mm}$ ZP group, there was a statistically significant decrease in $\Delta \mathrm{a}^{*}$ and a shift towards the blue axis, but the value was not large. In the $1.0 \mathrm{~mm}$ EM group, a statistically significant increase in the $\Delta \mathrm{E}^{*}$ value resulted in a substantial color change. All specimens showed a decrease in $\Delta \mathrm{L}^{*}$ and $\Delta \mathrm{a}^{*}$ and increase in $\Delta \mathrm{b}^{*}$ after glazing, becoming darker and exhibited a color change in the green-yellow direction (Table 4). A graph showing the color difference

\begin{tabular}{|c|c|c|c|c|c|}
\hline \multirow{2}{*}{ Thickness (mm)/glazing } & \multicolumn{2}{|c|}{ EM } & \multicolumn{2}{|c|}{ ZP } & \multirow{2}{*}{$P$ value } \\
\hline & Mean & $\mathrm{SD}$ & Mean & $\mathrm{SD}$ & \\
\hline $0.6 /$ not glazed & 30.37 & 1.31 & 33.03 & 1.79 & $.001^{*}$ \\
\hline 0.6/glazed & 35.07 & 1.53 & 34.10 & 1.43 & .162 \\
\hline 1.0/not glazed & 19.77 & 2.05 & 24.52 & 0.86 & $.000^{\star}$ \\
\hline 1.0/glazed & 21.76 & 2.75 & 24.72 & 1.12 & $.008^{\star}$ \\
\hline
\end{tabular}

Table 2. TP values and t-test results between materials in $0.6 \mathrm{~mm}$ and $1.0 \mathrm{~mm}$ thickness

EM: IPS e.max Press, ZP: IPS e.max ZirPress.

*Significantly different compared to test groups $(P<.05)$

\begin{tabular}{|c|c|c|c|c|c|c|}
\hline \multirow{2}{*}{ Material } & \multicolumn{2}{|c|}{ Not glazed } & \multicolumn{2}{|c|}{ Glazed } & \multirow{2}{*}{$P$ value } & \multirow{2}{*}{ Increased percentage } \\
\hline & Mean & $\mathrm{SD}$ & Mean & SD & & \\
\hline $0.6 \mathrm{~mm}$ EM & 30.37 & 1.31 & 35.07 & 1.53 & $.000^{\star}$ & 15.48 \\
\hline 0.6 mm ZP & 33.03 & 1.79 & 34.10 & 1.43 & .157 & 3.24 \\
\hline $1.0 \mathrm{~mm}$ EM & 19.77 & 2.05 & 21.76 & 2.75 & .084 & 10.07 \\
\hline 1.0 mm ZP & 24.52 & 0.86 & 24.72 & 1.12 & .652 & 0.82 \\
\hline
\end{tabular}

Table 3. TP values and paired t-test results of materials between before and after glazing in $0.6 \mathrm{~mm}$ and $1.0 \mathrm{~mm}$ thickness

EM: IPS e.max Press, ZP: IPS e.max ZirPress.

${ }^{\star}$ Significantly different compared to test groups $(P<.05)$ 


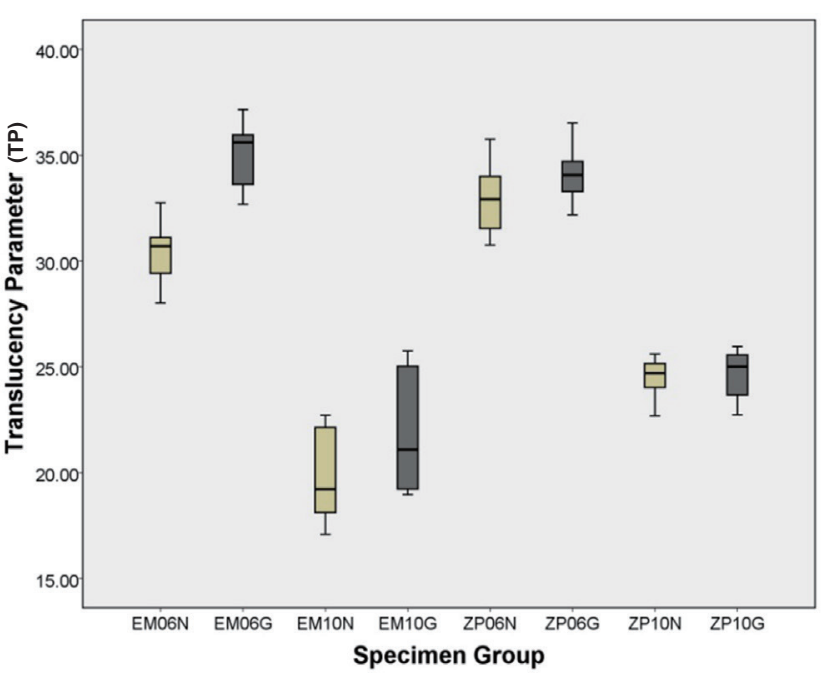

Fig. 1. TP changes of each experimental group; N: Not glazed, G: Glazed, EM: IPS e.max Press, ZP: IPS e.max ZirPress.

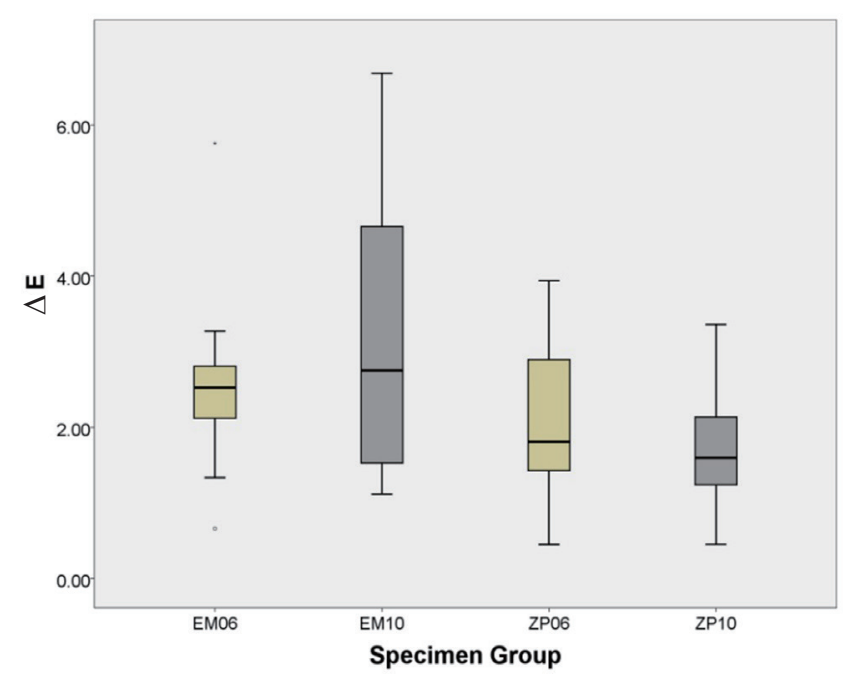

Fig. 2. Color difference $\left(\Delta \mathrm{E}^{*}\right)$ of each experimental group before and after glazing.

Table 4. Changes of color coordinates and t-test results of materials between before and after glazing of each thickness

\begin{tabular}{|c|c|c|c|c|c|c|}
\hline \multirow{2}{*}{ Thickness (mm) } & \multirow{2}{*}{ Color coordinate } & \multicolumn{2}{|c|}{ EM } & \multicolumn{2}{|c|}{ ZP } & \multirow{2}{*}{$P$ value } \\
\hline & & Mean & SD & Mean & SD & \\
\hline \multirow{4}{*}{0.6} & $\Delta \mathrm{L}^{*}$ & -2.28 & 1.55 & -0.92 & 1.15 & $.044^{*}$ \\
\hline & $\Delta a^{*}$ & -0.35 & 0.14 & -0.25 & 0.24 & .262 \\
\hline & $\Delta \mathrm{b}^{\star}$ & 0.36 & 0.93 & 0.23 & 1.88 & .847 \\
\hline & $\Delta \mathrm{E}^{\star}$ & 2.61 & 1.35 & 2.09 & 1.15 & .367 \\
\hline \multirow{4}{*}{1.0} & $\Delta \mathrm{L}^{*}$ & -1.16 & 0.79 & -1.33 & 1.02 & .675 \\
\hline & $\Delta \mathrm{a}^{*}$ & -0.01 & 0.12 & -0.34 & 0.17 & $.000^{*}$ \\
\hline & $\Delta b^{*}$ & 1.24 & 3.29 & 0.10 & 0.79 & .301 \\
\hline & $\Delta \mathrm{E}^{\star}$ & 3.17 & 1.88 & 1.65 & 0.87 & $.033^{*}$ \\
\hline
\end{tabular}

EM: IPS e.max Press, ZP: IPS e.max ZirPress.

*Significantly different compared to test groups $(P<.05)$

before and after glazing for each group and material is presented in Fig. 2. A comparison of the color change according to specimen thickness indicated a statistically significant but small decrease in $\Delta \mathrm{a}^{*}$ in the $0.6 \mathrm{~mm}$ EM group (Table 5).

Multiple regression was used to analyze the correlation between $\Delta \mathrm{E}^{*}$ and the color coordinates of the $0.6 \mathrm{~mm}$ and $1.0 \mathrm{~mm}$ specimens of the two materials, and the results are presented in Table 6. Analysis of EM resulted in a correlation of $\mathrm{R}=0.624$ with respect to the color coordinates. The regression line had the magnitude of the relation $\mathrm{R}^{2}$ of 0.389 and adjusted $\mathrm{R}^{2}$ of 0.275 , indicating an adjusted magnitude of the relation of $27.5 \%$. Of the relevant factors, $\Delta \mathrm{a}^{*}$ and $\Delta \mathrm{b}^{*}$ were not statistically significant, but $\Delta \mathrm{L}^{*}$ had an influence of -0.561 . In the ZP group, the correlation with the color coordinates was $\mathrm{R}=0.713$. The regression line had the $\mathrm{R}^{2}$ of 0.508 and adjusted $\mathrm{R}^{2}$ of 0.416 . Of the relevant factors, $\Delta \mathrm{a}^{*}$ and $\Delta \mathrm{b}^{*}$ were not statistically significant, but $\Delta \mathrm{L}^{*}$ had an influence, similar to EM. The influence of $\Delta \mathrm{L}^{*}$ was -0.650 . 
Table 5. Changes of color coordinates and t-test results of each thickness between before and after glazing of materials

\begin{tabular}{|c|c|c|c|c|c|c|}
\hline \multirow{2}{*}{ Material } & \multirow{2}{*}{ Color coordinate } & \multicolumn{2}{|c|}{$0.6 \mathrm{~mm}$} & \multicolumn{2}{|c|}{$1.0 \mathrm{~mm}$} & \multirow{2}{*}{$P$ value } \\
\hline & & Mean & SD & Mean & SD & \\
\hline \multirow{4}{*}{ EM } & $\Delta \mathrm{L}^{*}$ & -2.28 & 1.55 & -1.16 & 0.79 & .057 \\
\hline & $\Delta \mathrm{a}^{*}$ & -0.35 & 0.14 & -0.01 & 0.12 & $.000^{*}$ \\
\hline & $\Delta \mathrm{b}^{*}$ & 0.36 & 0.93 & 1.24 & 3.29 & .426 \\
\hline & $\Delta \mathrm{E}^{*}$ & 2.61 & 1.35 & 3.17 & 1.88 & .452 \\
\hline \multirow{4}{*}{ ZP } & $\Delta \mathrm{L}^{*}$ & -0.92 & 1.15 & -1.33 & 1.02 & .424 \\
\hline & $\Delta \mathrm{a}^{*}$ & -0.25 & 0.24 & -0.34 & 0.17 & .340 \\
\hline & $\Delta \mathrm{b}^{*}$ & 0.23 & 1.88 & 0.10 & 0.79 & .844 \\
\hline & $\Delta \mathrm{E}^{*}$ & 2.09 & 1.15 & 1.65 & 0.87 & .354 \\
\hline
\end{tabular}

EM: IPS e.max Press, ZP: IPS e.max ZirPress.

${ }^{*}$ Significantly different compared to test groups $(P<.05)$

Table 6. Multiple regression analysis for color difference $\left(\Delta \mathrm{E}^{*}\right)$ between before and after glazing of materials

\begin{tabular}{|c|c|c|c|c|c|c|c|}
\hline Material & Variables & $\mathrm{B}$ & Std. Error & $\beta$ & $\mathrm{t}$ & $P$ value & Dependent Variable: $\Delta \mathrm{E}^{\star}$ \\
\hline \multirow{3}{*}{ EM } & $\Delta \mathrm{L}^{*}$ & -0.682 & 0.250 & -0.561 & -2.734 & $.015^{\star}$ & \multirow{3}{*}{$\begin{array}{l}\mathrm{F}=3.401\left(P=.044^{*}\right) \\
\mathrm{R}=0.624, \mathrm{R}^{2}=0.389 \\
\text { Adj. } \mathrm{R}^{2}=0.275 \\
\text { Durbin-Watson }=1.811\end{array}$} \\
\hline & $\Delta \mathrm{a}^{*}$ & 2.610 & 1.542 & 0.346 & 1.693 & .110 & \\
\hline & $\Delta \mathrm{b}^{*}$ & 0.207 & 0.133 & 0.307 & 1.561 & .138 & \\
\hline \multirow{3}{*}{$\mathrm{ZP}$} & $\Delta \mathrm{L}^{*}$ & -0.593 & 0.166 & -0.650 & -3.575 & $.003^{*}$ & \multirow{3}{*}{$\begin{array}{l}\mathrm{F}=5.505\left(P=.009^{*}\right) \\
\mathrm{R}=0.713, \mathrm{R}^{2}=0.508 \\
\text { Adj. } \mathrm{R}^{2}=0.416 \\
\text { Durbin-Watson }=1.722\end{array}$} \\
\hline & $\Delta \mathrm{a}^{*}$ & 0.676 & 0.945 & -0.136 & -0.716 & .484 & \\
\hline & $\Delta \mathrm{b}^{*}$ & -0.110 & 0.138 & -0.151 & -0.797 & .437 & \\
\hline
\end{tabular}

EM: IPS e.max Press, ZP: IPS e.max ZirPress.

*Significantly different compared to test groups $(P<.05)$

\section{DISCUSSION}

An understanding of the translucency and optical properties of restorative materials is essential to the reproduction of the natural color of teeth. Esthetic materials used for indirect restorations are ideally adjustable in terms of their brightness, saturation, and hue as well as translucency based on the understanding of each factor. ${ }^{20}$ Standards concerning the appropriate translucency of restorative materials may vary across clinical situations. A highly translucent material would be suitable when modifying only the shape of an anterior tooth while retaining its natural color. In contrast, a material with a low translucency would be suitable if the aim is to block out the color of discolored tooth structure or an opaque core material underneath a restoration. Accordingly, it is necessary to consider optical properties in light of the clinical situation and purpose of treatment when selecting materials.

Of materials commonly used for anterior esthetic restoration, laminates tend to decrease in translucency when their hardness is increased. ${ }^{12}$ This makes it necessary to make an appropriate clinical selection after considering the physical and optical properties. Feldspathic porcelain shows the highest degree of translucency, ${ }^{4,11}$ but the addition of other composition to the glass matrix to improve its hardness undermines the esthetic appearance by reducing translucency On the other hand, the biggest advantage of lithium disilicate ceramic is that it can be made thin without compromising strength, and can be used to produce highly translucent and exceptionally esthetic prostheses. ${ }^{4}$

The present study aimed to examine changes in translucency, color, and other optical properties of two different ceramic laminate veneers before and after glazing. The EM was a lithium disilicate glass-ceramic ingot for use with the press technique, and ZP was a fluorapatite glass-ceramic for use with the press-on technique. The specimens were prepared to $0.6 \mathrm{~mm}$ and $1.0 \mathrm{~mm}$ in thickness. This was based on a report that the ordinary thickness of laminate veneers ranges from 0.3 to $0.9 \mathrm{~mm},{ }^{21}$ which gives a middle value of $0.6 \mathrm{~mm}$, and on an assumption that a veneer may be produced to $1.0 \mathrm{~mm}$ in thickness to modify the shape of a tooth. 
Previous studies regarding the translucency of dental ceramics indicated that the roughness of the specimen surface strongly affects the material's translucency. ${ }^{22,23}$ The final translucency of a ceramic prosthesis is achieved through the glazing process, which produces the smoothest surface. ${ }^{5}$ The results of the present study indicate that the fluorapatite ZP was more translucent than the lithium disilicate EM in all groups except the glazed $0.6 \mathrm{~mm}$ group. Heffernan $e t$ $a l^{10}$ reported that glazing decreases the opacity and increased the translucency of veneer ceramics on core materials. Another study using lithium disilicate reported that while the glazing process may have an effect on thin specimens, there was no change in the $0.9 \mathrm{~mm}$ group and therefore the process had no effect. ${ }^{17}$ The present study obtained similar results; the $0.6 \mathrm{~mm}$ EM group exhibited a change in the form of increased translucency, but the $1.0 \mathrm{~mm}$ group did not show a statistically significant change. For ZP, however, there was no statistical difference between the $0.6 \mathrm{~mm}$ and $1.0 \mathrm{~mm}$ groups, suggesting that the effects of glazing are exhibited differently according to the composition of the materials.

Jeong et al. ${ }^{24}$ studied the translucency of zirconia-based pressable ceramics with different cores and veneer thicknesses. Translucency varied according to differences in the leucite, fluorapatite, and lithium-disilicate crystalline structures, and this was interpreted as being due to differences in the shape and volume of the crystals inside each glass ceramic. Moreover, the fluorapatite-based veneer showed a higher translucency than the lithium disilicate-based veneer in specimens with a veneer thickness of $0.5 \mathrm{~mm} .{ }^{24}$ In the present study, the unglazed $0.6 \mathrm{~mm}$ group exhibited a statistically significant difference, and fluorapatite-based veneer had a significantly higher translucency in the two $1.0 \mathrm{~mm}$ groups. The two studies differed in their experimental design but showed similar trends.

Possible explanations for the larger increase in TP after glazing in the thinner specimens are that the effects of glazing are located deeper inside the thicker specimens, or that there is a certain limit to the increase in TP after glazing regardless of thickness. ${ }^{15}$ In the present study, only the 0.6 $\mathrm{mm}$ EM was statistically significant and the $1.0 \mathrm{~mm}$ EM did not produce significant results. This result is consistent with a report speculating that the change in TP is only marginal in specimens of a certain thickness or greater. ${ }^{17}$ It also agrees with a finding that glazing did not produce significant differences in translucency among $1.5 \mathrm{~mm}$ thick specimens made of veneered cores. ${ }^{25}$ However, the lack of a statistically significant change in TP in the $0.6 \mathrm{~mm}$ ZP group suggests that the change in TP varies according to the composition. According to Chu et al., ${ }^{11}$ changes in thickness directly influence the brightness of ceramic restorations. Although TP tends to decrease as thickness increases, ${ }^{4,8,13}$ the largest change in brightness is observed when the surface smoothness of a material is changed by glazing, ${ }^{9}$ and this may be linked to the change in TP. The process is also known to increase flexural strength by increasing surface smoothness and reducing internal porosity. ${ }^{20}$

Each material exhibited varying color differences and color coordinate changes before and after glazing. The 0.6 $\mathrm{mm}$ EM showed a larger decrease in $\Delta \mathrm{L}^{*}$ and became darker. This is consistent with the results of a study that used specimens of $0.6-0.9 \mathrm{~mm}$ in thickness. ${ }^{17}$ After excluding $\Delta \mathrm{a}^{*}$, which showed only a slight change in the $1.0 \mathrm{~mm}$ group, $\Delta \mathrm{E}^{*}$ was larger in the EM group. Clinically, it should be noted that the color changes can vary more in lithium disilicate veneers than in fluorapatite veneers. Also, since EM10 group showed wider range of color change than EM06, color variance should be given a more careful consideration when the prosthesis is thicker. According to previous reports, a $\Delta \mathrm{E}^{*}$ value of 1 represents a color change perceivable by $50 \%$ of observers under controlled conditions. ${ }^{26} \mathrm{~A} \Delta \mathrm{E}^{*}$ value of 2.72 represents a change perceivable by ordinary observers or patients ${ }^{27}$ while the clinically permitted $\Delta \mathrm{E}^{*}$ value between $\Delta \mathrm{E}^{*} \leq 3.3^{28}$ and $\Delta \mathrm{E}^{*} \leq 3.7 .{ }^{29}$ Based on such literature, all groups in the present study produced color differences before and after glazing that would be perceivable by ordinary observers or patients depending on the situation. This means that when using a veneer restoration in a clinical setting, it may be necessary to check the color by conducting a trial before glazing.

Other than a slight change in the $\Delta \mathrm{a}^{*}$ value of the EM group, there were no statistically significant color changes before and after glazing according to thickness in the same material. As such, additional analysis only examined the correlation between the color changes of the two materials. The results indicated that $\Delta \mathrm{L}^{*}$ influenced $\Delta \mathrm{E}^{*}$ in both $\mathrm{EM}$ and ZP. This is slightly different from previous research, such as the study that measured $0.6 \mathrm{~mm}$ lithium disilicate specimens from two different manufacturers, ${ }^{16}$ which reported that $\Delta \mathrm{L}^{*}$ and $\Delta \mathrm{b}^{*}$ affect the results of various thicknesses of lithium disilicate. ${ }^{17}$

The clinical fabrication processes of ceramic laminate veneers involve many steps other than glazing, each of which affects the final color. According to research, sandblasting and laser treatment of the veneer surface for cementation resulted in increased opacity, but TP of the veneer treated with fluoride was not affected. These effects were greater in thinner veneers. ${ }^{30}$ Thus, in actual clinical settings, it is necessary to consider color changes after each process of cementation.

The present study was limited to specimens produced to the A1 shade of lithium disilicate and fluorapatite. The thicknesses of the specimens were also discontinuous and restricted. Changes in translucency and color after glazing was quantitatively predicted only to a limited extent. Moreover, textural changes following glazing was outside the scope of current study, and thus not put into consideration. Future studies will need to focus on a wide variety of clinical situations including a diverse range of composition, the influence of different types of glazing agents and models capable of predicting TP and color changes for various colors and thicknesses. 


\section{CONCLUSION}

In this study, TP differences before and after glazing were observed depending on the thickness and composition of the ceramic laminate veneer. In general, ceramic veneers showed increased translucency with glazing. Color differences and varying degree of changes in color coordinates after glazing was noted depending on the composition of the materials.

\section{ORCID}

Sung-Joon Kim https://orcid.org/0000-0003-0603-4036

Jae-Man Woo bttps://orcid.org/0000-0001-7209-186X

Chan Woo Jo https://orcid.org/0000-0003-4777-0080

Ju-Hee Park bttps://orcid.org/0000-0001-9251-5287

Soo Kyung Kim https://orcid.org/0000-0002-0631-5148

Se Hoon Kahm https://orcid.org/0000-0001-6945-8480

\section{REFERENCES}

1. Ryu SY, Lim JH, Cho IH. A study on the color stability of porcelain for porcelain fused to metal crown. J Korean Acad Prosthodont 2000;38:73-84.

2. Joiner A. Tooth colour: a review of the literature. J Dent 2004;32:3-12.

3. Al Ben Ali A, Kang K, Finkelman MD, Zandparsa R, Hirayama $\mathrm{H}$. The effect of variations in translucency and background on color differences in CAD/CAM lithium disilicate glass ceramics. J Prosthodont 2014;23:213-20.

4. Barizon KT, Bergeron C, Vargas MA, Qian F, Cobb DS, Gratton DG, Geraldeli S. Ceramic materials for porcelain veneers: part II. Effect of material, shade, and thickness on translucency. J Prosthet Dent 2014;112:864-70.

5. Yilmaz C, Korkmaz T, Demirköprülü H, Ergün G, Ozkan Y. Color stability of glazed and polished dental porcelains. J Prosthodont 2008;17:20-4.

6. Wiskott HWA. Fixed prosthodontics: principles and clinics. London, UK: Quintessence publishing; 2011. p. 670-1.

7. Choi BB, Woo YH, Kim HS. Contemporary fixed prosthodontics. 3rd ed. Seoul, Korea: Jisung Publishing; 2003. p. 645 .

8. Yilmaz K, Gonuldas F, Ozturk C. The effect of repeated firings on the color change of dental ceramics using different glazing methods. J Adv Prosthodont 2014;6:427-33.

9. Obregon A, Goodkind RJ, Schwabacher WB. Effects of opaque and porcelain surface texture on the color of ceramometal restorations. J Prosthet Dent 1981;46:330-40.

10. Heffernan MJ, Aquilino SA, Diaz-Arnold AM, Haselton DR, Stanford CM, Vargas MA. Relative translucency of six all-ceramic systems. Part II: core and veneer materials. J Prosthet Dent 2002;88:10-5.

11. Chu FC, Chow TW, Chai J. Contrast ratios and masking ability of three types of ceramic veneers. J Prosthet Dent 2007; 98:359-64.

12. Spear F, Holloway J. Which all-ceramic system is optimal for anterior esthetics? J Am Dent Assoc 2008;139:19S-24S.
13. Kim SJ, Son HH, Cho BH, Lee IB, Um CM. Translucency and masking ability of various opaque-shade composite resins. J Dent 2009;37:102-7.

14. Sinmazisik G, Demirbas B, Tarcin B. Influence of dentin and core porcelain thickness on the color of fully sintered zirconia ceramic restorations. J Prosthet Dent 2014;111:142-9.

15. Kim SJ, Kahm SH. Translucency of ceramic veneers on glazing effect. J Korean Acad Prosthodont 2015;53:138-43.

16. Kahm SH, Lee BJ, Seo MS, Kim SJ. Color difference of lithium disilicate ceramic veneer on glazing effect. Oral Biol Res 2016;40:124-8.

17. Kahm SH, Heo UC, Kim SJ. Color change of lithium disilicate ceramic veneer on different thicknesses with and without glazing. Oral Biol Res 2017;41:8-14.

18. British standard specification for dental porcelains for jacket crowns. BS5612. London, UK: British Standard Institution; 1978.

19. Johnston WM, Ma T, Kienle BH. Translucency parameter of colorants for maxillofacial prostheses. Int J Prosthodont 1995;8:79-86.

20. Santos MO, do Amaral FL, França FM, Basting RT. Influence of translucence/opacity and shade in the flexural strength of lithium disilicate ceramics. J Conserv Dent 2015;18:394-8.

21. Bagis B, Turgut S. Optical properties of current ceramics systems for laminate veneers. J Dent 2013;41:e24-30.

22. Wang H, Xiong F, Zhenhua L. Influence of varied surface texture of dentin porcelain on optical properties of porcelain specimens. J Prosthet Dent 2011;105:242-8.

23. Awad D, Stawarczyk B, Liebermann A, Ilie N. Translucency of esthetic dental restorative CAD/CAM materials and composite resins with respect to thickness and surface roughness. J Prosthet Dent 2015;113:534-40.

24. Jeong ID, Bae SY, Kim DY, Kim JH, Kim WC. Translucency of zirconia-based pressable ceramics with different core and veneer thicknesses. J Prosthet Dent 2016;115:768-72.

25. Kurtulmus-Yilmaz S, Ulusoy M. Comparison of the translucency of shaded zirconia all-ceramic systems. J Adv Prosthodont 2014;6:415-22.

26. Kuehni RG, Marcus RT. An experiment in visual scaling of small color differences. Color Res Appl 1979;4:83-91.

27. Ragain JC, Johnston WM. Color acceptance of direct dental restorative materials by human observers. Color Res Appl 2000;25:278-85.

28. Ruyter IE, Nilner K, Moller B. olor stability of dental composite resin materials for crown and bridge veneers. Dent Mater 1987;3:246-51.

29. Johnston WM, Kao EC. ssessment of appearance match by visual observation and clinical colorimetry. J Dent Res 1989; 68:819-22.

30. Turgut S, Bagis B, Ayaz EA, Korkmaz FM, Ulusoy KU, Bagis YH. How will surface treatments affect the translucency of porcelain laminate veneers? J Adv Prosthodont 2014;6:8-13. 